\title{
Interdisciplinary Education in Language Universities - A Survey on Postgraduate Students' Attitude and Its Implications
}

\author{
Qian $\mathrm{Li}^{1}$ \\ ${ }^{1}$ Guangdong University of Foreign Studies, China \\ Correspondence: Qian LI, Guangdong University of Foreign Studies, China. E-mail: lqchristina@gdufs.edu.cn
}

Received: June 21, 2020

Accepted: July 25, $2020 \quad$ Online Published: July 30, 2020

doi:10.5539/hes.v10n3p94

URL: https://doi.org/10.5539/hes.v10n3p94

\begin{abstract}
The current rapid development of economy and technology calls for the cultivation of interdisciplinary talents in universities. When faced with this challenge, language universities, as a specialized type, need to take a range of factors into consideration, among which language students' attitudes play a crucial role for further course design. This present study carried out a survey among students in the major language universities in China, and analyzed the results to identify students' attitudes to interdisciplinary education. Results show half of the students are positive about the implementation of interdisciplinary education, however they lack the knowledge about what interdisciplinary education is and how it is carried out. The problems are discussed and a series of suggestions are proposed in order to promote the interdisciplinary program in language universities efficiently and effectively.
\end{abstract}

Keywords: interdisciplinary education, language universities, students attitude

\section{Introduction}

Within the framework of one-belt-one-road economy, cooperation between countries become more frequent and significant, and communication between different language speakers appears to be common and crucial. This calls for a large number of language majors who are well trained in multiple disciplines. Inter-disciplinary talents are those who are familiar with theories and methods from a variety of related subject fields and can apply the theories and methods into academic and social practice (Zhan and Xu, 2010). The present study focuses on the cultivation of interdisciplinary talents in language universities and explores the current knowledge about and the attitude towards interdisciplinary education among language students.

\section{Status Quo of Interdisciplinary Postgraduate Education}

Interdisciplinary postgraduate education has received researchers and educators' attention in different countries. Universities have adopted a variety of ways for the implementation of interdisciplinary education. Currently, interdisciplinary education in different countries exhibits distinctive features to promote a more efficient cultivation of interdisciplinary talents.

In the United States, two categories of subject courses have been set under each majors: inter-discipline courses and general subject courses. Many research universities in the States promote the training of inter-disciplinary postgraduates by means of the establishment of multiple project laboratories. MIT, for instance, has formed the College of Science Technology and Social Planning so as to carry out a series of interdisciplinary training and research among natural, technique science, and human arts. UCLA carried out the general education scheme which encompasses general education courses serving the whole university students. The general education scheme provides modules on natural science, social science, arts and human science and the related paradigm and cognitive methods in those fields. Specifically, a range of disciplines have been classified into three types of knowledge: arts, humanities and social science; engineering, healthy science, mathematics and other natural science; bridge knowledge to encourage students to explore the interconnection between science, culture and society. It is worth mentioning that the bridge knowledge serves as the connection between human and natural science. In such a scheme, students have the opportunities to establish a comprehensive framework covering multiple disciplines. Bridge knowledge, in this sense, serves as the interconnection between general education courses and specific 
major courses. All the above three types of knowledge were compulsory to all the students in the university(Spelt et al., 2009).

In Britain, a series of interdisciplinary courses are designed for postgraduates. In addition, students are encouraged to carry out research studies on inter-disciplinary topics (Warren, 2016). For instance, In Sterling University, the master course for environment science was carefully designed to be highly integrated-- the five compulsory courses and four selective courses cover all the related fields in environmental science. In German, Berlin Industry University placed much emphasis on the systematicity and comprehensiveness of postgraduate courses, and designed a large number of modules to include both human \& social sciences and natural sciences. In the University of Tsukuba, several major discipline groups have been formed so as to carry out interdisciplinary research. Nagoya University in Japan creates a flexible postgraduate education system which consists of a fundamental category and an interdisciplinary category, and the former is made up of 18 fundamental courses, while the latter of 7 courses from different disciplines (IIvanitskaya et al., 2012).

Relatively speaking, the interdisciplinary postgraduate education in China is at a developing stage which needs more exploration and research. In 1999, the first interdisciplinary research institute was established at Tianjin Normal University which launched the enrolment of interdisciplinary masters. The twenty-fist century witnessed the progress of interdisciplinary postgraduate education in China. In Peking University, a cross-discipline research institute was established in 2003 to train postgraduates on a range of cross-discipline fields, e.g. biological information, biological medical science.

When language universities are concerned, their major responsibility is the cultivation of language professionals plus related disciplinary skills and knowledge to meet the demand of contemporary social development. In the current situation of "one belt and one road", language professionals are in great need, given the fact that a variety of languages are involved in those countries. There exist 40 official languages among the one-belt and one-road countries. We may first make a comparison among the four well-known language universities in China, and see how many languages are taught to language majors in those universities. The five language universities are: Beijing Foreign Studies University (BFSU), Shanghai International Studies University (SISU), Guangdong University of Foreign Studies (GDUFS), Xi'an International Studies University (XISU). Figure 1 shows that BFSU has set 30 languages as different language majors, SISU 21 languages, GDUFS 20 languages, and XISU 26 languages. Those universities teach most of the official languages in the one-belt and one-road countries. However, languages taught in the universities are still not sufficient to meet the demand for the overall collaboration among the one-belt-one-road countries. There are around 10 languages which were not taught at those language universities. A need for majors in minor languages is clearly presented.

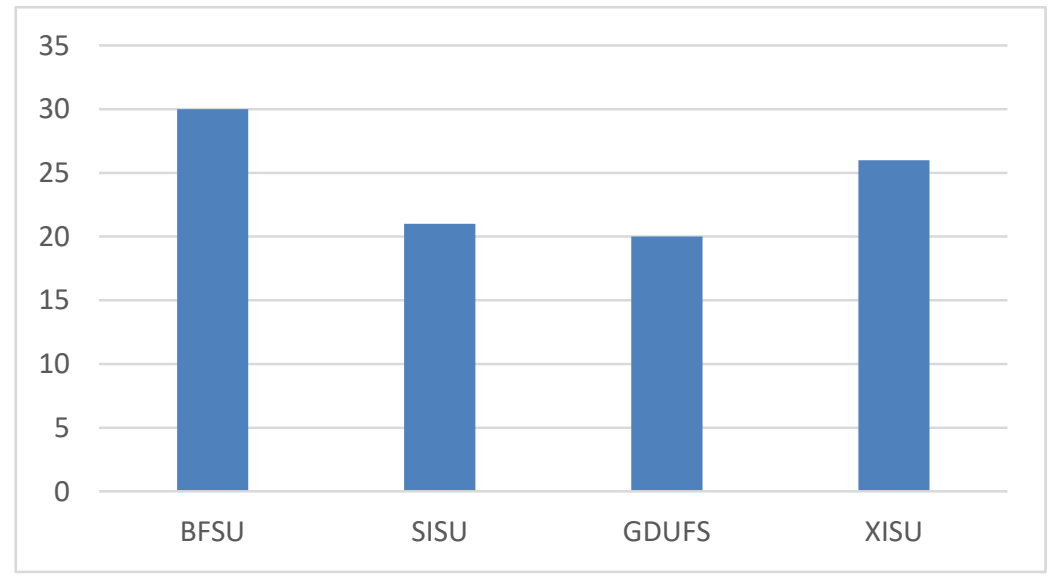

Figure 1. Numbers of languages as majors in four universities

In addition, the knowledge of a language itself is not adequate in such an age when artificial intelligence tends to play the role of language translators in many fields. The cultivation of interdisciplinary language professionals comes out to be a new task for language universities. Language universities in China are exploring the ways of cross disciplinary course design with different focuses. BFSU has set general courses for postgraduates of different language majors. The three courses are World Literature, General Linguistics 
and International Political Issues. SISU has proposed the program featured as "multiple languagest" strategy. Students are instructed to master at least two foreign languages for intercultural communication; "+" refers to the additional disciplines which students are expected to be trained in of. As an example, SISU has recently launched the bachelor-degree program of data science and big data technology. This program appears as an interdisciplinary education covering a variety of subjects, including language, finance, computer science, and big data technology. In GDUFS, a series of interdisciplinary instruction has been carried out. The cross discipline programs include the master programs of Forensic Linguistics (law+linguistics), Business English (business+language), Computerized Linguistics (computer science+ linguistics).

We can see the efforts of language universities in terms of interdisciplinary talents cultivation. Correspondingly, when the above programs are implemented, a crucial factor needs to be explored-- as the recipient of those programs, what is the attitude of the language majors towards interdisciplinary education.

\section{The Present Study}

For a sound practice in interdisciplinary education, this study attempts to explore the postgraduates' attitudes towards interdisciplinary education in language universities. Specifically, at first, a questionnaire survey was carried out among language graduates and their responses was analyzed. Secondly, based on the analysis of the survey results, a series of implications and suggestions concerning interdisciplinary education are proposed.

\subsection{The Survey}

One hundred and sixty-two language postgraduates from the above-mentioned four language universities have responded to the questionnaire which was distributed via online platform and their responses are listed as follows.

Question 1: Have you ever got interdisciplinary education in your university?

Figure 2 shows that more than half (58\%) of the respondents seldom or never got any interdisciplinary education in the universities. Most language majors spent most of their time concentrating on language related courses. A relatively small proportion $(35 \%)$ of the students have received certain degree of interdisciplinary education.

These results may be due to the following two facts: a. students were not clear about the definition of interdisciplinary education, so they cannot identify which courses are cross-disciplinary. b. the design of interdisciplinary courses was not comprehensive enough. As a result, this type of instruction was not common among language majors.

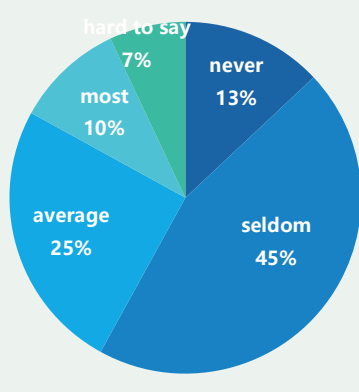

Figure 2. Current interdisciplinary education

Question 2: Do you prefer to receive interdisciplinary postgraduate education?

It shows that more than $60 \%$ of the students (33\% strongly agree $+28 \%$ agree) preferred to receive interdisciplinary education. By contrast, some students (5\% strongly disagree $+13 \%$ disagree) did not wish to be involved in different disciplines, and a roughly same proportion of students (21\%) were not sure about the function of cross disciplinary courses (see Figure 3 ).

It is reasonable to witness a positive attitude to the interdisciplinary education among a larger number of students. More and more language majors realize the mere application of language in their future work 
cannot satisfy the demand of the current society. For those students who were unwilling to be involved in more disciplines, the reasons may be a) they were not well aware of the benefits of multiple disciplinary education; or b) they did not hope to distribute their time and effort among disciplines other than their majors, so as to concentrate most on the majors for a better outcome.

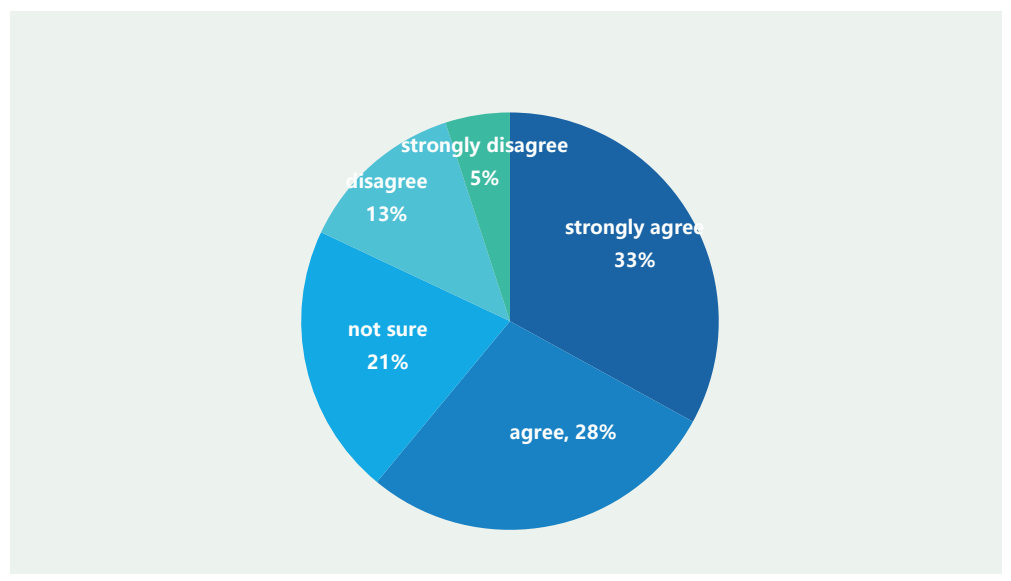

Figure 3. Attitude towards possible interdisciplinary education

Question 3: As a postgraduate majoring in languages, which type of interdisciplinary course mode do you prefer?
a. Major courses + optional courses $(\mathrm{M}+\mathrm{opt})$
b. Major courses + compulsory courses $(\mathrm{M}+\mathrm{comp})$
c. Multiple general courses (general)

In this question, three types of course delivery methods were selected by the respondents. As shown in Figure 4, the provision of general courses covering a variety of disciplines were the top preference (45\%). Most general courses are mainly the fundamental/introductory courses from different disciplines, and are designed to face students from all the majors. Therefore, it is not surprising to see their popularity among students. As compared with the availability of compulsory courses concerning other disciplines, the optional courses were more welcomed by $42 \%$ of all students. This result reveals a preference for flexibility in course selection. In addition to their major courses, compulsory courses from other disciplines did not enjoy popularity among students $(13 \%)$, which may be due to the fact that compulsory courses place additional demand on students in terms of course credits, or course achievement.

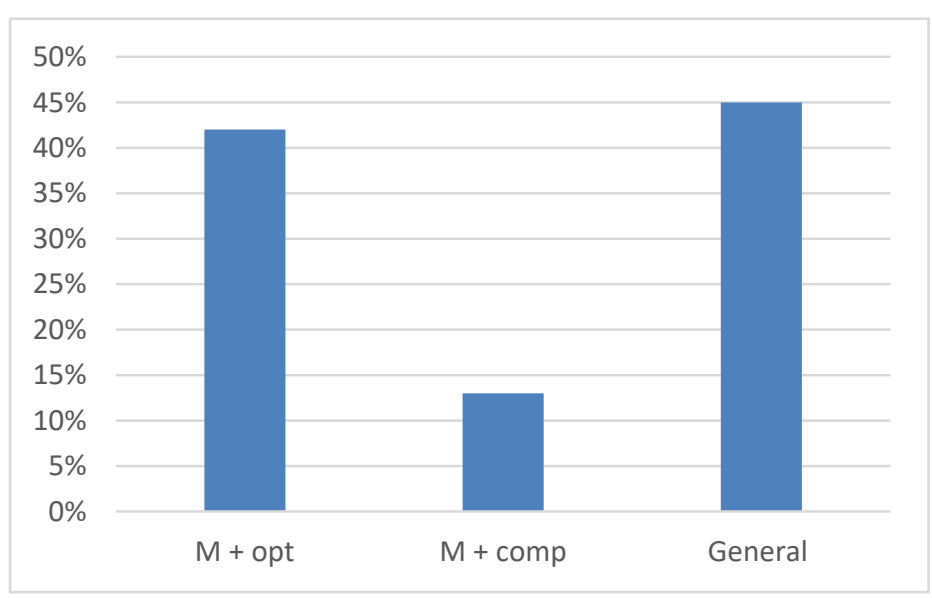

Figure 4. Preferred course delivery methods

Question 4: If interdisciplinary courses are provided by different colleges, which cooperation mode do you prefer? 
The three cooperation modes reflect the differences in cooperation scope. Figure 5 shows, around $60 \%$ of all the respondents preferred the cooperation between colleges in the same university. The advantage is evident: the courses will be delivered by multiple major professors from different colleges, at the same time it will not be too complicated for students to choose courses across universities. About $30 \%$ of the students chose the cooperation between universities. This may be due to the reason that when two or more universities are involved, it may be expected that more courses from different majors will be provided, although at the same time more factors in teaching and administrative issues need to be taken into account. Less than $10 \%$ of the students chose the cooperation within a college. In most universities, especially the language ones, a college focuses on a single discipline. If interdisciplinary courses are offered by the same college, it may not be treated as cross disciplinary in a strict sense.

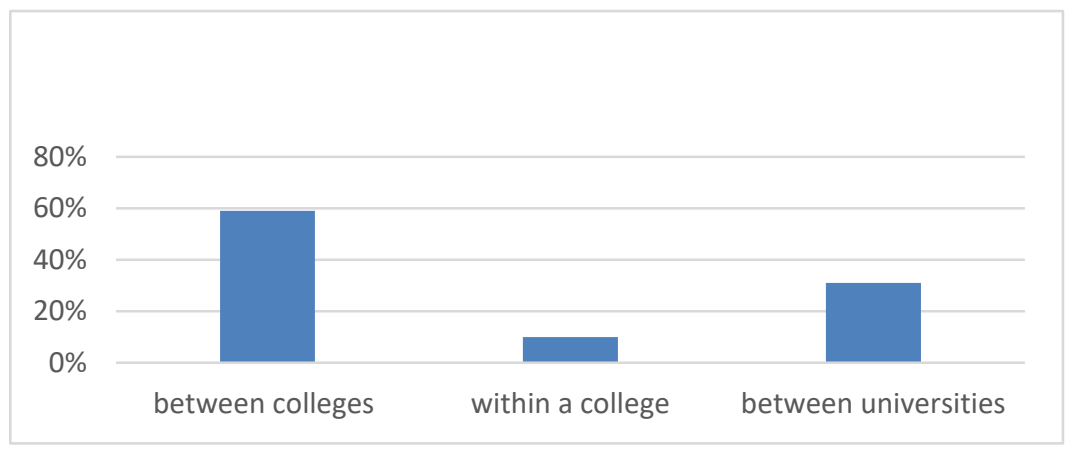

Figure 5. Preferred cooperation mode

Question 5: Do you agree with the following statement:

Interdisciplinary education among postgraduates will lead to a better employment for them.

As shown in Figure 6, more than half of the respondents (31\% strongly agree+ $24 \%$ agree) were positive about the role of interdisciplinary education in seeking a better job. To meet the requirement of modern social development, being well equipped with knowledge and skills covering several disciplines were treated as an obvious advantage by most students. In contrast, $45 \%$ students were not sure about the benefits of cross disciplinary education, and this is similar to the uncertainty about the effects of the newly-appeared course design mode on further employment.

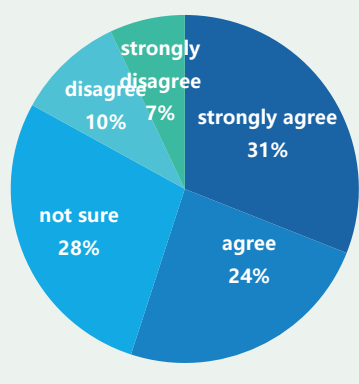

Figure 6. Interdisciplinary influence on future employment

Question 6: Do you agree with the following statement:

Interdisciplinary education among postgraduates will bring about a better academic development.

Different from the positive attitude in the above question, respondents were more conservative about the benefits of interdisciplinary education for academic development. In Figure 7, we can see that about $80 \%$ respondents (35\% disagree+ $12 \%$ strongly disagree+ $32 \%$ not sure) did not think that the cross-field education would play a supportive role in academic development. This may derive from the current research situation-- when languages are concerned, most research topics or research programs are 
concentrated on one single field.

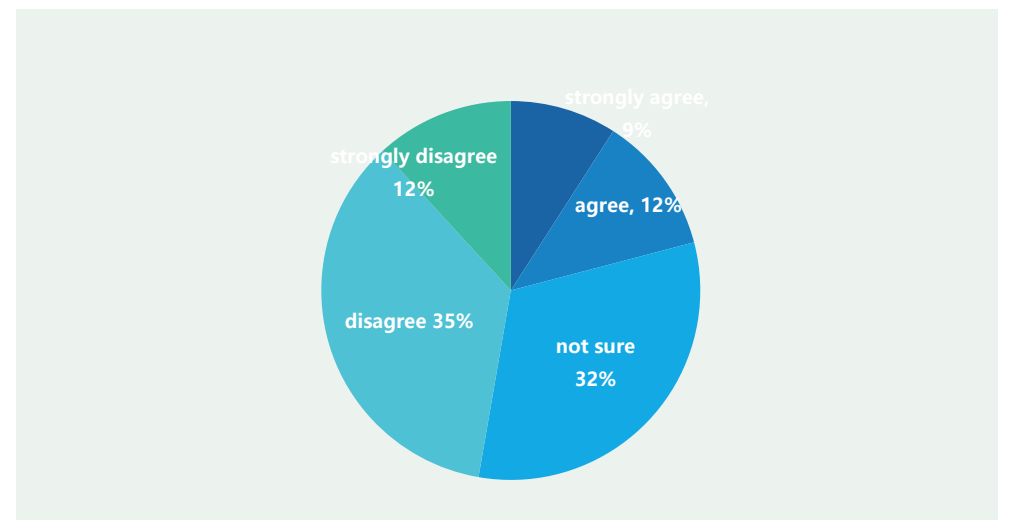

Figure 7. Interdisciplinary education influence on future academic development

\section{Problems and Implications for Further Development}

In this study, the survey among postgraduate students in language universities shows the attitude towards the interdisciplinary education for language majors. Although more than half of the respondents are positive about the necessity of the interdisciplinary instruction, most of them do not have the access to this opportunity at their schools. Around half of the students do not see the advantage of such education for academic research, whereas students are positive about the benefits of interdisciplinary education for future work. As for the course mode, more students prefer the course cooperation between different colleges at the same university, and hope that the courses from multiple disciplines can be offered in the form of general courses facing a range of major varieties.

The analysis on the attitudes of postgraduate students towards interdisciplinary education reveals a series of problems as follows:

a. Students are not clear about the definition of interdisciplinary education, so they cannot identify which courses are cross-disciplinary;

b. The scope of interdisciplinary courses is not wide enough. Consequently, this type of instruction is not common among language majors;

c. Students are not well aware of the benefits of multiple disciplinary education. Therefore they do not hope to distribute much time and effort among disciplines other than their majors.

Given the lack of interdisciplinary instruction practice in language universities, there is a great need for more action in this field. The rapid development of technology and world communication calls for the cultivation of interdisciplinary professionals. Education on language alone is not sufficient and needs to encompass multiple related fields, such as economy, technology, politics, and culture (Yu, 2018). The design of the interdisciplinary courses needs to take more factors into account during the training process of language majors.

The fact that students are not well informed of the essence, the contents, the scope and the advantages of interdisciplinary education calls for more attention to the proactive action in universities (Xu, 2004). As compared with the traditional course design, interdisciplinary education involves more cross fields knowledge and skills. It is advisable that students with interests in interdisciplinary subjects are given priority consideration in the enrollment of the related programs. A match between the courses and students' interests may play a significant role in the outcome of interdisciplinary training in language universities.

Furthermore, it is noteworthy that the collaboration system between different colleges and universities is of crucial importance for the development of interdisciplinary education (Biggs, 2003). The survey shows the students' preference to collaboration between different colleges in the same university. This reflects a more feasible way of education resources sharing. As compared to the collaboration between universities, college collaboration is likely to offer a variety of advantages in terms of course design, construction of professional teaching team, and the cross-disciplinary course selection.

Interdisciplinary education, as a newly launched education mode, is gaining more and more attention from 
universities. Different from the comprehensive universities, language universities needs to consider the essence of language training plus other related knowledge and skills. It is expected that students' attitude to the interdisciplinary education is necessarily considered when such interdisciplinary courses are designed in language universities. Further studies in terms of students need analysis are expected to offer a more comprehensive information for the development of interdisciplinary education.

\section{Acknowledgements}

This study is supported by Postgraduates Educational Creative Program of Guangdong University of Foreign Studies 19GWYJSCX-01.

\section{References}

Biggs, J. B. (2003). Teaching for quality learning at university: what the student does (2nd Ed.), Buckingham: Open University Press.

IIvanitskaya, L., Clark, D., \& Montgomery, G. (2012). Interdisciplinary learning: Process and Outcomes. Innovative Higher Education, 27, 95-111. https://doi.org/10.1023/A:1021105309984

Spelt, E., Biemans, H. A., \& Tobi, H. (2009). Teaching and learning in interdisciplinary higher education: A systematic review. Educational Psychology Review, 21, 365-378. https://doi.org/10.1007/s10648-009-9113-z

Warren, K. (2016). Postgraduate veterinary training in conservation medicine: an interdisciplinary program. Ecohealth, 1, 57-65. https://doi.org/10.1007/s10393-005-0004-6

$\mathrm{Xu}$, Q. S. (2004). Talents cultivation and university organization. Liaoning Education Research, 10, 127-139.

Yu, G. E., \& Liu, H. B. (2018). Course design optimization for cross-disciplinary postgraduates' creative ability. Research on China Higher Education, 15, 48-52.

Zhan, L. J., \& Xu, Q. S. (2010). Status quo and development trend of interdisciplinary postgraduate education. China Higher Education, 4, 58-60.

\section{Copyrights}

Copyright for this article is retained by the author(s), with first publication rights granted to the journal.

This is an open-access article distributed under the terms and conditions of the Creative Commons Attribution license (http://creativecommons.org/licenses/by/4.0/). 